\title{
Usability testing and satisfaction of "The Patient Access": A mobile health application for patients with venous thromboembolic disease. A pilot study
}

\author{
Piotr Merks ${ }^{1,2,3,8}$, Urszula Religioni ${ }^{4}$, Karolina Arciszewska, ${ }^{5,6}$, \\ Walentyn Pankiewicz ${ }^{5}$, Miłosz Jaguszewski ${ }^{7,8}$, Regis Vaillancourt ${ }^{9}$ \\ ${ }^{1}$ Faculty of Medicine, Collegium Medicum, Cardinal Stefan Wyszynski University, Warsaw, Poland \\ ${ }^{2}$ Department of Pharmaceutical Technology, Faculty of Pharmacy, Collegium Medicum in Bydgoszcz, Poland \\ ${ }^{3}$ Scientific Consortium of Cardinal Stefan Wyszynski University with Piktorex Sp. z o.o. in Warsaw, \\ Collegium Medicum, Cardinal Stefan Wyszynski University, Warsaw, Poland \\ ${ }^{4}$ Collegium of Business Administration, Warsaw School of Economics, Warsaw, Poland \\ ${ }^{5}$ Pharmacy "Pod Gryfem“, Bialystok, Poland \\ ${ }^{6}$ Faculty of Organic Chemistry, Medical University of Bialystok, Poland \\ ${ }^{7}$ First Department of Cardiology, Medical University of Gdansk, Poland \\ ${ }^{8}$ Polish Pharmaceutical Group SA, Lodz, Poland \\ ${ }^{9}$ Children's Hospital of Eastern Ontario, ON, Canada
}

This paper was guest edited by Prof. Krzysztof J. Filipiak

Venous thromboembolic disease (VTE) is a challenging issue in medicine and for public health [1]. VTE is the third most common cardiovascular disease after ischemic heart disease and ischemic stroke. Approximately half of the patients with symptomatic, untreated venous thrombosis develop pulmonary embolism, and $10 \%$ of cases end in sudden death. Death in untreated patients is about $30 \%$. However, after initiating treatment, it decreases to $3-8 \%$ [2].

It is particularly challenging to ensure the effectiveness of therapy for patients with VTE. Most patients, due to comorbidities, take many medications, which carries the risk of interactions and other drug-related problems. An additional issue is adherence to therapy. Patients often do not achieve satisfactory health results due to non-adherence. They usually take medicine incompletely, inconsistently, or not at all. Polypharmacy, inappropriate prescription, and drug-related problems increase morbidity and mortality rates and contribute to a large waste of health resources. All these situations require effective action to improve the quality of patient care [3].
A practical solution for patients is the use of various mHealth (mobile health) technologies [4]. mHealth is a sub-segment of eHealth and is defined as the use of mobile computing and communication technologies (e.g., mobile phones, wearable sensors) for health services and information [5]. mHealth includes various methods of interaction with the patient - text messages, reminders, but also phone applications.

Many studies are confirming the impact of mHealth applications on improving patient outcomes in different populations and at varying levels of healthcare. Applications are particularly important for chronically ill patients, including the elderly.

Currently, many mHealth applications are available for patients. They support prevention diagnostics, patient monitoring, correct use of medicines, as well as communication between the patient and healthcare staff [5]. mHealth is used in patients with diabetes, chronic obstructive pulmonary disease, or cardiovascular diseases, including hypertension, atrial fibrillation, or stroke patients.

Address for correspondence: Dr. Piotr Merks, Faculty of Medicine, Collegium Medicum, Cardinal Stefan Wyszynski University, ul. Wóycickiego1/3, 01-938 Warszawa, Poland, tel: +48602101979, e-mail: p.merks@uksw.edu.pl 
Table 1. Descriptive statistics of System Usability Scale (SUS) results.

\begin{tabular}{|c|c|c|c|c|c|}
\hline No. of SUS question & M & Median & SD & Min & Max \\
\hline 1. I think that I would like to use this system frequently & 2.81 & 3 & 1.11 & 1 & 4 \\
\hline 2. I found the system unnecessarily complex & 1.88 & 1.5 & 1.11 & 1 & 4 \\
\hline 3. I thought the system was easy to use & 4.35 & 5 & 1.11 & 2 & 5 \\
\hline $\begin{array}{l}\text { 4. I think that I would need the support of a technical person } \\
\text { to be able to use this system }\end{array}$ & 1.75 & 1 & 1.13 & 1 & 4 \\
\hline 5. I found the various functions in this system were well integrated & 4.13 & 4 & 0.81 & 3 & 5 \\
\hline 6. I thought there was too much inconsistency in this system & 1.94 & 2 & 0.93 & 1 & 4 \\
\hline $\begin{array}{l}\text { 7. I would imagine that most people would learn to use this } \\
\text { system very quickly }\end{array}$ & 4.31 & 5 & 0.87 & 3 & 5 \\
\hline 8. I found the system very cumbersome to use & 1.69 & 1 & 1.01 & 1 & 4 \\
\hline 9. I felt very confident using the system & 3.31 & 3 & 1.25 & 1 & 5 \\
\hline $\begin{array}{l}\text { 10. I needed to learn a lot of things before I could get going } \\
\text { with this system }\end{array}$ & 2.13 & 2 & 1.20 & 1 & 5 \\
\hline
\end{tabular}

$\mathrm{M}$ - average value; SD — standard deviation; Min — minimum value; Max — maximum value

According to available research, there are no mobile applications dedicated to patients with VTE disease. Given the seriousness of this disease, a decision was made to develop a mobile application for patients with VTE disease. "The Patient Access" is an application that enables the correct and safe use of medicine for people with VTE disease. The application displays all drug information in written and graphic forms. It also has the function of drug reminders and is a compendium of knowledge about VTE disease. The application significantly increases the likelihood that patients will use medications as directed, which is especially important when taking any drug.

To date, the functionality and usability of "The Patient Access" mobile application has been verified and will support safe drug dosing for people with VTE disease.

Testing the application involved assessing the usability of a prototype, allowing users to explore the application in detail and formulate conclusions about both the prototype and the final shape of the product. Testing was performed by a target group of product users [6].

After an application demonstration, each participant was asked to answer the questions included in the System Usability Scale (SUS). SUS contains ten statements related to the subjective assessment of utility. The participant assigns points to each statement (according to the Likert 5-point scale) assessing the extent to which he agrees with the statement. SUS has a good façade validity and high reliability (Cronbach's alpha 0.91) [7, 8].

This study took place at a community pharmacy in Bialystok, Poland. Participants were recruited among persons buying anticoagulants at the pharmacy. Study participants had to regularly use a smartphone or tablet, which ensured that they the basic skills in operating new technologies. The age of study participants ( $>18$ years) was also an important criterion. Data were collected from March to May 2020.

Sixteen further potential users of the application took part in the study. Sample sizes for testing the usability of a high-fidelity prototype require only 5-10 participants to identify $80 \%$ of product problems $[9,10]$. For this reason, 16 people participating in the study were a sufficient number. The average age of the subjects was $64.44(\mathrm{SD}=15.56)$. The respondents mainly had a higher education $(81.25 \%)$.

After calculating the score according to the SUS scale key, the overall assessment of usability of "The Patient Access" application was rated at 73.59 points.

Analyzing the average score to each statement in the SUS questionnaire (Table 1), it can be assessed that most patients agreed with the statements regarding the ease of use of the application and proper integration of functions:

_ "Ithought the system was easy touse" $(\mathrm{M}=4.35$; $\mathrm{SD}=1.11$;

— "I would imagine that most people would learn to use this system very quickly" ( $\mathrm{M}=4.31$; $\mathrm{SD}=0.87$;

- "I found the various functions in this system were well integrated” $(\mathrm{M}=4.13 ; \mathrm{SD}=0.81)$.

Respondents, disagreed most with statements regarding the inconvenience of use, the need to help another person when using the application, or excessive system complexity: 
- "I found the system very cumbersome to use" $(\mathrm{M}=1.69 ; \mathrm{SD}=1.01)$;

- "I think that I would need the support of a technical person to be able to use this system" ( $\mathrm{M}=1.75 ; \mathrm{SD}=1.13)$;

- "I found the system unnecessarily complex" $(\mathrm{M}=1.99 ; \mathrm{SD}=1.11)$.

This project is innovative because it was the first to focus on creating an application supporting drug dosage in people with VTE disease. This usability and satisfaction research allowed us to validate this application before the market launch. "The Patient Access" application has been highly rated by potential users. Users also indicated those features that should be developed in the next phase of work on the application.

Funding: This was supported by an education grant from Boehringer Ingelheim, Vienna, Austria.

Conflict of interest: The content outlined herein, represents the individual opinions of the authors and may not necessarily represent the viewpoints of their employers. Piotr Merks is employed as CEO of Piktorex sp. $z$ o.o., is employed at the Cardinal Stefan Wyszynski University in Warsaw, Poland, Department of Pharmacy, Collegium Medicum in Bydgoszcz and as an Advisor of the management board for Research and Innovation at the Polish Pharmaceutical Group S.A. Miłosz Jaguszewski is employed as a University Professor at the First Department of Cardiology, Medical University of Gdansk, Poland and Scientific Officer at Polish Pharmaceutical Group SA and as such, authors must stress that this additional study was done purely for academic interest only and must not be construed in any way as an investment recommendation.

\section{References}

1. ISTH Steering Committee for World Thrombosis Day. Thrombosis: a major contributor to the global disease burden. J Thromb Haemost. 2014; 12(10): 1580-1590, doi: 10.1111/jth.12698, indexed in Pubmed: 25302663.

2. Kapitan-Malinowska B, Bogołowska-Stieblich A. Żylna choroba zakrzepowo-zatorowa. Post Nauk Med. 2009; 5: 345-354.

3. Mangin D, Bahat G, Golomb BA, et al. International Group for Reducing Inappropriate Medication Use \& Polypharmacy (IGRIMUP): Position Statement and 10 Recommendations for Action. Drugs Aging. 2018; 35(7): 575-587, doi: 10.1007/s40266018-0554-2, indexed in Pubmed: 30006810.

4. Petrovic M, Somers A, Marien S, Spinewine A. Optimization of drug use in older people: a key factor for a successful ageing. In: The Cambridge Handbook of Successful Aging. Cambridge University Press, Cambridge 2019: 237-262.

5. Burke LE, Ma J, Azar KMJ, et al. Current science on consumer use of mobile health for cardiovascular disease prevention: a scientific statement from the American Heart Association. Circulation. 2015; 132(12): 1157-1213, doi: 10.1161/ CIR.0000000000000232, indexed in Pubmed: 26271892.

6. Stinson JN, Jibb LA, Nguyen C, et al. Development and testing of a multidimensional iPhone pain assessment application for adolescents with cancer. J Med Internet Res. 2013; 15(3): e51, doi: 10.2196/jmir.2350, indexed in Pubmed: 23475457.

7. Bangor A, Kortum P, Miller J. Determining what individual SUS scores mean: adding an adjective rating scale. J Usability Studies. 2009; 4(3): 114-123.

8. Brooke J. SUS - A quick and dirty usability scale [online]. Usability Evaluation in Industry. http://hell.meiert.org/core/pdf/sus. pdf (Accessed May 2, 2020).

9. Lewis JR. Sample sizes for usability studies: additional considerations. Hum Factors J Hum Factors Ergon Soc. 1994; 36(2): 368378, doi: 10.1177/001872089403600215, indexed in Pubmed: 8070799.

10. Sauro J. 10 Things To Know About The System Usability Scale (SUS) [online]. http://www.measuringusability.com/blog/10things-SUS.php (May 2, 2020). 